\title{
A novel Asp380Ala mutation in the GLC1A/myocilin gene in a family with juvenile onset primary open angle glaucoma
}

Wellcome Ocular Genetics Unit, Department of Genetics, Trinity College, Dublin 2, Ireland

A M Kennan

F C Mansergh

P F Kenna

P Humphries

G J Farrar

Department of Ophthalmology, University of Iowa College of Medicine, Iowa City, IA, USA

J H Fingert

T Clark

\section{Fundacion Jimenez} Diaz, Clinica de Nuestra Senora de la Concepcion, Avda de los Reyes Catolicos 2 (Ciudad

Universitaria), 28040

Madrid, Spain

C Ayuso

Research Foundation, Eye and Ear Hospital, Dublin 2, Ireland P F Kenna

Correspondence to: Dr Kennan.

\begin{abstract}
Avril M Kennan, Fiona C Mansergh, John H Fingert, Tamara Clark, Carmen Ayuso,
\end{abstract} Paul F Kenna, Peter Humphries, G Jane Farrar

\begin{abstract}
Glaucoma describes a clinically and genetically heterogeneous group of diseases that result in optic neuropathy and progressive loss of visual fields. A gene for juvenile onset primary open angle glaucoma (JOAG) has recently been mapped to 1q21-31. Mutations in the trabecular meshwork induced glucocorticoid response gene (TIGR, also known as myocilin or the GLC1A locus) have been found to cause both juvenile and later onset primary open angle glaucoma. Family TCDPOAG1 is a Spanish kindred, which segregates JOAG in an autosomal dominant fashion. This family was found to be linked to the previously identified GLC1A locus on chromosome 1q. Direct sequencing of the TIGR/myocilin gene showed a heterozygous $A$ to $\mathbf{C}$ transition in codon 380 , resulting in the substitution of alanine for aspartic acid (Asp380Ala). This substitution created a StyI restriction site, which segregated with the JOAG phenotype and permitted rapid screening of all members of the family. This restriction site was not present in 60 controls.

$(\Im$ Med Genet 1998;35:957-960)
\end{abstract}

Keywords: glaucoma; TIGR; myocilin

The term glaucoma encompasses a heterogeneous group of optic neuropathies which bring about loss of visual field and which, if left untreated, can lead to total blindness. Glaucoma has been subdivided into various categories, depending on factors such as the age of onset, the shape of the iridocorneal angle, and whether or not the glaucoma is primary or secondary in nature. The most frequently observed form of the disease is primary open angle glaucoma, or POAG, which affects approximately $2 \%$ of the population over the age of 45 years. ${ }^{12}$ Characteristics of POAG include atrophy of the optic nerve as a result of degeneration of the retinal ganglion cells and resulting progressive loss of visual field. Losses in visual field are often preceded and accompanied by raised intraocular pressures; however, the trabecular meshwork is usually normal in appearance ${ }^{1-3}$ POAG varies in its age of onset and has been classified (somewhat arbitrarily) into juvenile onset primary open angle glaucoma (JOAG) and the more frequently observed later onset form, chronic primary open angle glaucoma (COAG) ${ }^{45}$
Several loci have been implicated in the aetiology of various forms of glaucoma. Regions implicated in adult onset POAG have been mapped to chromosomes 2cen-q13 $3^{6}$ and $3 \mathrm{q} 21-24 .^{7}$ The pigment dispersion syndrome, of which JOAG is a feature, has recently been mapped to $7 \mathrm{q} 35-\mathrm{q} 36{ }^{8} \mathrm{~A}$ form of POAG also cosegregates with the nail patella syndrome (NPS) locus on 9q34. ${ }^{9}$ Open angle glaucoma associated with iris and iridocorneal angle abnormalities has been linked to $4 \mathrm{q} 25^{10}$ and 6p25. ${ }^{11-13}$ Primary congenital glaucoma has been mapped to $1 \mathrm{p} 36,2 \mathrm{p} 21$, and the terminal region of $6 \mathrm{p}^{14 \cdot 16}$ The cytochrome P4501B1 gene has been found to be mutated in cases of primary congenital glaucoma that map to $2 \mathrm{p} 21 .{ }^{17}$ The first locus for the condition (named GLC1A) was placed on 1q21-31 by a large number of studies and the critical region was eventually narrowed to $3 \mathrm{cM} .{ }^{41823}$

Recently, mutations in the TIGR gene (trabecular meshwork inducible glucocorticoid response protein), which maps on 1q, have been associated with glaucoma in both JOAG and COAG patients. ${ }^{24-30}$ This protein is expressed in the trabecular meshwork, cilary body, and sclera ${ }^{24}$ and has also been shown to be expressed at lower levels in the choroid, heart, and skeletal muscle. ${ }^{324}$ TIGR has been shown to be identical to an independently isolated myosin-like protein named myocilin, which was identified from a retina specific cDNA library and was found to be expressed in the interconnecting cilia of photoreceptor cells. ${ }^{24}{ }^{31}$ (Note: previous usage of the acronym TIGR led to the suggestion that the gene be referred to as myocilin and/or GLC1A. Henceforth the gene is referred to as myocilin in this text.)

Myocilin is encoded by a gene with three exons and two introns and is 504 amino acids in length. ${ }^{32}$ Putative structural features include various specific promoter motifs, a signal sequence for secretion, putative sites thought to be involved in cell-cell and glycoprotein interactions, an $\mathrm{N}$-terminal hydrophobic region, a myosin-like domain, a leucine zipper, probably involved in homodimerisation, and a C-terminal olfactomedin-like domain. ${ }^{32}$ To date, the vast majority of the mutations have been confined to exon 3, which encodes the olfactomedin-like C-terminal domain. ${ }^{24}$

Here we describe a large Spanish family (TCD-POAG1) segregating autosomal dominant JOAG (fig 1) with a novel Asp380Ala mutation in the myocilin gene. All family 


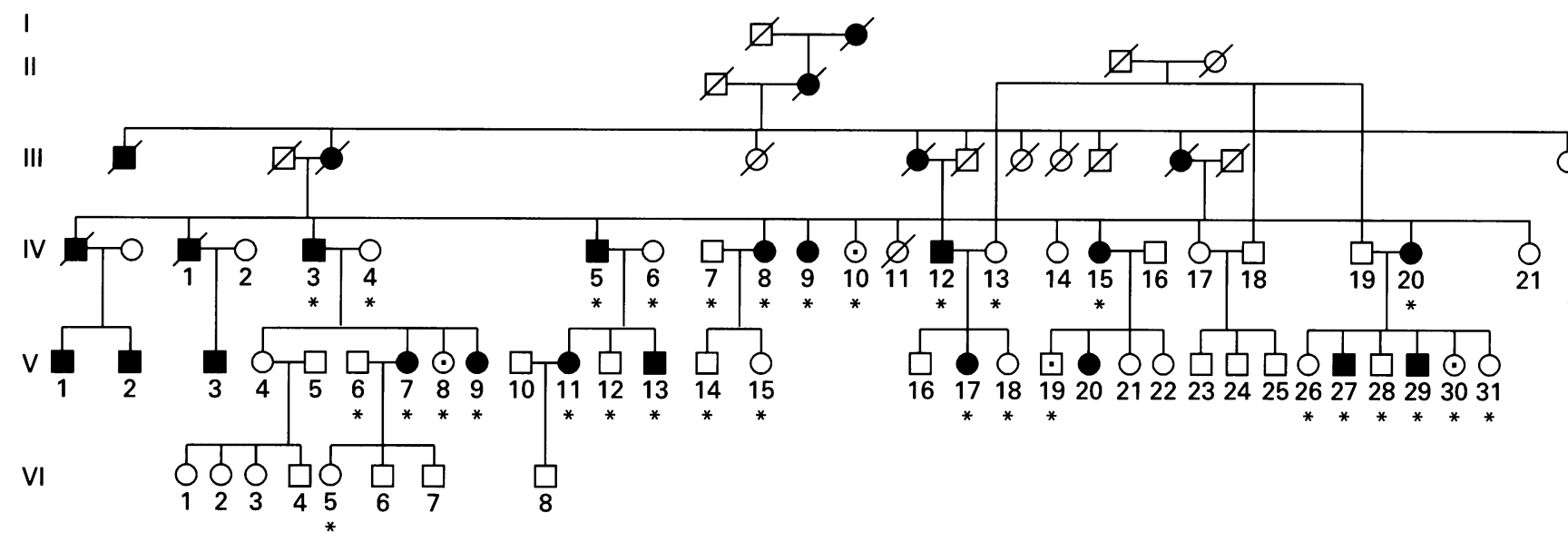

Figure 1 Family TCD-POAG1. Spanish juvenile onset glaucoma pedigree. Subjects used in analysis are marked with an asterisk. Those whose diagnostie status was uncertain are marked with a small dot in the middle of a white circle or square.

members for whom DNA samples were available were clinically assessed at the Fundacion Jimenez Diaz in Madrid, Spain. Initial diagnosis of affected subjects was made, in most cases, on the basis of raised intraocular pressures, which were often above $30 \mathrm{~mm} \mathrm{Hg}$ and sometimes above $40 \mathrm{~mm} \mathrm{Hg}$. Medically uncontrolled raised intraocular pressures and continuing loss of visual field have necessitated drainage operations in many of the patients, usually within the third and fourth decades. Diagnosis of patients, extraction of DNA, PCR, direct sequencing, and linkage analysis were carried out as previously described. ${ }^{30}$

Amplification and sequencing primers ( $\left.5^{\prime}-3^{\prime}\right)$ were as follows: TIGRA Fwd: GAACTCGAACAAACCTGGGA, TIGRA Revs: CATGCTGCAGTACTTATAGCGG, TIGRB Fwd: ATACTGCCTAGGCCACTGGA, TIGRB Revs: CAATGTCCGTGTAGCCACC, TIGRex3.3 Fwd: TGGCTACCACGGACAGTTC, TIGRex3.3 Revs: CATTGGCGACTGACTGCTTA.

An aliquot of each PCR product was digested with 20 units of StyI (New England Biolabs) at $37^{\circ} \mathrm{C}$ overnight with the buffer supplied by the manufacturers. Samples were analysed on $2.5 \%$ ethidium bromide stained agarose gels.

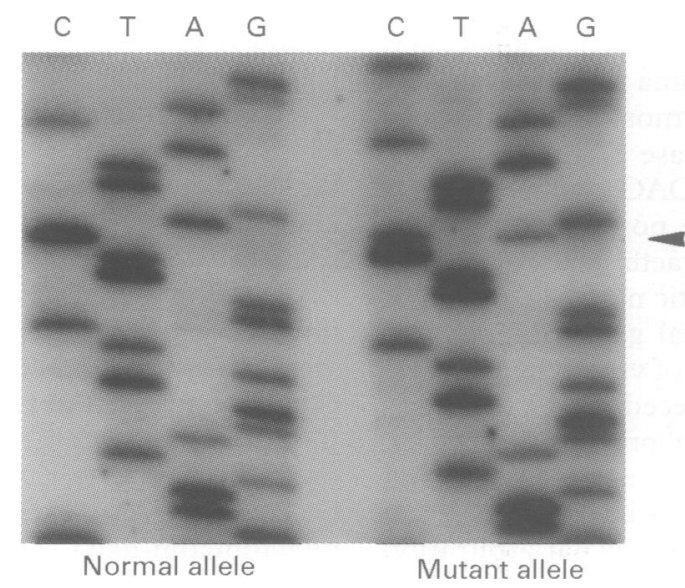

Figure 2 Partial nucleotide sequence from a genomic PCR amplification product of exon 3 of the TIGR gene showing a heterozygous $C$ to $A$ substitution. Reverse sequence for both normal and affected subjects is shown.
Family TCD-POAG1 was found to showe linkage to the previously identified GLC1A locus on chromosome 1q with a $Z$ max of $5.47 \%$ at $0 \%$ recombination with marker $\mathrm{D} 1 \mathrm{~S} 242$ (not shown). Multipoint analysis gave a $\mathrm{Zmax}$ of just over 6 in the interval flanked by the markers D1S2658 and D1S2659. The reo ported involvement of the myocilin gene in the aetiology of glaucoma prompted the screening of the coding regions of the gene in affected members of this family. Direct sequencing ofe two affected family members showed a hetero 90 zygous $\mathrm{A}$ to $\mathrm{C}$ transition in codon 380 resulting in the substitution of alanine for aspartic acid (fig 2). This substitution created a StyI restric $\bar{\partial}$ tion site which permitted rapid screening of al: members of the family and confirmed that the mutation segregated with the JOAG phenotype (fig 3). The restriction site was not present in 60 unrelated CEPH controls. Therefore, these data suggest that the Asp380Ala amino acid. change is the cause of JOAG in this pedigree.
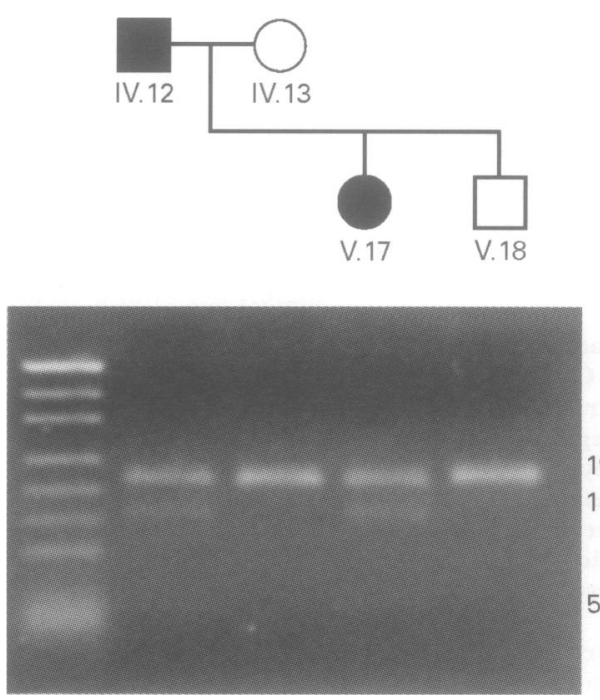

Figure 3 StyI digestion of genomic 197 bp PCR amplification products of exon 3 . The gel shows a small family group within TCD-POAG1 with two affected subjects, IV.12 and V.17, and two unaffected subjects, IV.13 ? and V.18. Digestion of the disease allele yields fragments of $143 \mathrm{bp}$ and $54 \mathrm{bp}$ in length while the unaffected allele remains uncut. Lane 1 contains the molecular weight marker Puc 19 cut with MspI. Note: the 54 bp fragment is difficult to visualise. 
The fact that this substitution results in the replacement of an acidic and hydrophilic amino acid by a neutral and hydrophobic one is further evidence that the Asp380Ala mutation may disrupt the secondary structure of myocilin to pathogenic effect. Further evidence to this effect involves comparisons between myocilin and three related proteins from the bullfrog, rat, and $C$ elegans: OLF, NORP, and F11C3.2. ${ }^{24}$ This amino acid sequence alignment shows that the aspartic acid residue at position 380 of TIGR is conserved in all four proteins. $^{24}$

The inheritance of JOAG has previously been described as autosomal dominant with reduced penetrance. ${ }^{13}$ There are no cases within this pedigree of persons who have inherited the disease mutation and who do not have glaucoma. However, four family members were initially diagnosed as affected and have since been found not to carry the Asp380Ala mutation. Subject V.30 was diagnosed with high IOP and glaucomatous field changes at 18 years and has been operated on to control the progression of disease. However, she has been found to have closed angle glaucoma. Subject V.8 was diagnosed as affected on the basis of mild visual field defects; however, her IOP was normal. Subject V.19 was diagnosed as affected on the basis of high IOP and asymmetrical cupping of the optic discs. Subject IV.10 was diagnosed at the age of 47 (later than is usual for the rest of the family) with high IOP and diffuse reduction of sensitivity in the visual fields. With the exception of V.30, the remaining three anomalous subjects have mild symptoms of glaucoma and, before mutational analysis, were classified as "unknown" for the purposes of linkage analysis. Given that younger members of the family are at high risk of developing glaucoma, intense medical scrutiny could have resulted in the misdiagnosis of some of these people as affected on marginal grounds. Alternatively, given the mildness and later onset of symptoms observed in IV.10, V.8, and V.19 and the high frequency of later onset POAG in the population, it is entirely possible that they represent phenocopies of the more severe disease noted in those with the Asp380Ala mutation.

A growing number of mutations in myocilin have now been implicated in both JOAG and adult onset POAG. ${ }^{2524-30}{ }^{33}$ Discovery of further mutations within this gene should assist in the identification of those at risk of developing glaucoma before the development of significant visual dysfunction. Further understanding of its biochemistry and functions may lead to the development of improved medication for glaucoma and possibly to the identification of further genes involved in its pathogenesis.

The support of Alcon Laboratories Inc is gratefully acknowledged. One of us (FM) held a Health Research Board of Ireland Studentship. The Ocular Genetics Unit of Trinity College Dublin is also supported by the Wellcome Trust, the Health Research Board of Ireland, the Ulverscroft Foundation, and the Bryan Guinness Charitable Trust. We would also like to thank Drs Garcia-Sandoval and Rodriguez-Bermejo for all their help Drs Garcia-Sandoval and Rodriguez-Bermejo
with the clinical details of family TCD-POAG1.
1 Raymond V. Molecular genetics of the glaucomas: mapping of the first five GLC loci. Am ₹ Hum Genet 1997;60:272-7. 2 Stone EM, Fingert JH, Alward WLM, et al. Identification of a gene that causes primary open angle glaucoma. Science 1997;275:668-70.

3 Sarfarazi M. Recent advances in molecular genetics of glaucomas. Hum Mol Genet 1997;6:1667-77.

4 Morrissette J, Cote G, Anctil JL, et al. A common gene for juvenile and adult onset primary open angle glaucomas juvenile and adult onset primary open angle glaucomas confined

Dubois S, Morissette J, Winstall E, et al. Important phenotypic variability of the Lys $423 \mathrm{Glu}$ mutation in the TIGR gene within a huge GLC1A-linked glaucoma family. $\mathrm{Am}$ Hum Genet Suppl 1997;61:1939.

6 Stoilova D, Child A, Trifan OC, Crick RP, Coakes RL, Sarfarazi M. Localization of a locus (GLC1B) for adult-onset primary open angle glaucoma to the 2 cen-q13 region. Grimary open angle glau $1996 ; 36: 142-50$

7 Wirtz MK, Samples JR, Kramer PL, et al. Mapping a gene for adult-onset primary open angle glaucoma to chromosome 3q. Am F Hum Genet 1997;60:296-304.

8 Andersen JS, Pralea AM, DelBono EA, et al. A gene responsible for the pigment dispersion syndrome maps to chromosome 7q35-q36. Arch Ophthalmol 1997;115:384-8

9 McIntosh I, Lichter PR, Clough MV, et al. Glaucoma and nail-patella syndrome (NPS) cosegregate: one gene or two? Am f Hum Genet Suppl 1987;61:58.

10 Heon E, Sheth BP, Kalenak JW, et al. Linkage of autosomal dominant iris hypoplasia to the region of the Riege syndrome locus (4q25). Hum Mol Genet 1995;4:1435-9.

11 Jordan T, Ebenezer N, Manners R, McGill J, Bhattacharya S Familial glaucoma iridogoniodysplasia maps to a $6 \mathrm{p} 25$ region implicated in primary congenital glaucoma and iridoregion inclicar in prina

2 gears AJ, Mirzayans F, Gould DB, Pearce WG, Walter MA Autosomal dominant iridogoniodysgenesis anomaly maps to $6 \mathrm{p} 25$. Am ₹ Hum Genet 1996;59:1321-7.

13 Morissette J, Falardeau P, Dubois S, et al. A common gene for developmental and familial open angle glaucomas confined on chromosome 6p25. Am ₹ Hum Genet Suppl 1997 61:1670.

14 Sarfarazi M, Akarsu AN, Hossain A, et al. Assignment of a locus (GLC3A) for primary congenital glaucoma (buphthalmos) to $2 \mathrm{p} 21$ and evidence for genetic heterogeneity. Genomics 1995;30:171-7.

15 Akarsu AN, Turacli ME, Aktan SG, et al. A second locus (GLC1B) for primary congenital glaucoma (buphthalmos) maps to the 1 p36 region. Hum Mol Genet 1996;5:1199203.

16 Nishimura DY, Patil S, Alward WLM, Stone EM, Sheffield VC. Fine mapping of the chromosomal breakpoints in an individual with congenital glaucoma and a 6:13 translocation. Invest Ophthalmol Vis Sci 1995;36:2574.

17 Stoilov I, Akarsu AN, Sarfarazi M. Identification of three different truncating mutations in cytochrome P4501B (CYP1B1) as the principal cause of primary congenita glaucoma (buphthalmos) in families linked to the GLC $3 A$ locus on chromosome 2p21. Hum Mol Genet 1997;6:641-7.

18 Sheffield VC, Stone EM, Alward WLM, et al. Genetic linkage of familial open angle glaucoma to chromosome 1q21q31. Nat Genet 1993;4:47-50.

19 Richards JE, Lichter PR, Boehnke M, et al. Mapping of a gene for autosomal dominant juvenile-onset open angle glaucoma to chromosome 1q. Am ₹ Hum Genet 1994;54:62-70.

20 Wiggs JL, Haines JL, Paglinauan C, Fine A, Sporn C, Lou $D$. Genetic linkage of autosomal dominant juvenile glaucoma to $1 \mathrm{q} 21-31$ in three affected pedigrees. Genomics 1994;21:299-303.

21 Meyer A, Valtot F, Bechetoille A, et al. Linkage between juvenile glaucoma and chromosome $1 \mathrm{q}$ in two French families. C R Acad Sci (Paris) 1994;317:565-70.

22 Graff C, Urbak SF, Jerndal T, Wadelius C. Confirmation of linkage to 1q21-31 in a Danish autosomal dominant juvenile-onset glaucoma family and evidence of genetic heterogeneity. Hum Genet 1995;96:285-9.

23 Sunden SLF, Alward WLM, Nichols BE, et al. Fine mapping of the autosomal dominant juvenile open angle glaucoma (GLC1A) region and evaluation of candidate genes. Genome Res 1996;6:862-9.

24 Adam MF, Belmouden A, Binisti $P$, et al. Recurren mutations in a single exon encoding the evolutionarily conserved olfactomedin-homology domain of TIGR in familia open angle glaucoma. Hum Mol Genet 1997;6:2091-7.

25 Mansergh FC, Kenna PF, Ayuso C, Kiang AS, Humphrie $P$, Farrar GJ. Two novel mutations in the TIGR gene in primary open angle glaucoma. Am $\mathcal{f}$ Hum Genet Suppl 1997;61:1670.

26 Fingert JH, Clark TD, Beck G, et al. Characterization of the glaucoma phenotypes associated with two mutations in the Glaucoma phenotypes associated with two mutations

27 Raymond V, Clepet C, Dubois S, et al. Normal homozygotes for primary open angle glaucoma caused by the TIGR GLC1A gene: evidence for a new form of dominance in man. Am $\mathcal{F}$ Hum Genet Suppl 1997;61:101.

28 Stoilova D, Child A, Brice G, Crick RP, Fleck BW, Sarfaraz $M$. Identification of a new TIGR mutation in a family with juvenile onset open angle glaucoma. Ophthal Genet 1997;18:109-18.

29 Michels-Rautenstrauss K, Mardin CY, Budde WM, et al. Autosomal dominant juvenile open angle glaucoma (GLC1A): fine mapping of the TIGR gene to 1q24.3-25.2 and identification of a novel mutation in a German family. Am ₹ Hum Genet Suppl 1997;61:1992. 
30 Mansergh FC, Kenna PF, Ayuso C, Kiang AS, Humphries P, Farrar GJ. Novel mutations in the TIGR gene in early and late onset open angle glaucoma. Hum Mutat 1998;11: 244-51.

31 Kubota R, Noda S, Wang Y, et al. A novel myosin-like protein (myocilin) expressed in the connecting cilium of the photoreceptor molecular cloning, tissue expression, and chromosomal mapping. Genomics 1997;41:360-9.
32 Polansky JR, Fauss DJ, Chen P, et al. Cellular pharmacology and molecular biology of the trabecular meshwork inducible glucocorticoid response gene product. Ophthalmologica 1997;211:126-39.

33 Wiggs JL, Allingham RR, Vollrath D, et al. Frequency oR mutations in TIGR in families with juvenile and adul onset primary open angle glaucoma. Am f Hum Genet Suppl 1997;61:2054. 